\title{
Rapid thermal annealing of sputter-deposited ZnO:Al films for microcrystalline Si thin-film solar cells
}

\author{
H. Koshino ${ }^{1}$, Z. Tang ${ }^{1}$, S. Sato ${ }^{1}$, H. Shimizu ${ }^{2}$, Y. Fujii ${ }^{3}$, T. Hanajiri ${ }^{3}$, and H. Shirai ${ }^{1}$, a \\ 1 Graduate School of Science and Engineering, Saitama University, 255 Shimo-Okubo, Sakura, 338-8570 Saitama, Japan \\ 2 Saitama Industrial Technology Centre (SAITEC) 3-12-28 Kami-Aoki, Kawaguchi, 333-0844 Saitama, Japan \\ 3 Bio-Nano Electronics Research Centre, Toyo University, 2100 Kujirai, Kawagoe, 350-8585 Saitama, Japan
}

Received: 14 July 2011 / Accepted: 2 March 2012

Published online: 26 June 2012

\begin{abstract}
Rapid thermal annealing of sputter-deposited $\mathrm{ZnO}$ and $\mathrm{Al}$-doped $\mathrm{ZnO}$ (AZO) films with and without an amorphous silicon (a-Si) capping layer was investigated using a radio-frequency (rf) argon thermal plasma jet of argon at atmospheric pressure. The resistivity of bare ZnO films on glass decreased from $10^{8}$ to $10^{4}-10^{5} \Omega \mathrm{cm}$ at maximum surface temperatures $T_{\max } \mathrm{s}$ above $650{ }^{\circ} \mathrm{C}$, whereas the resistivity increased from $10^{-4}$ to $10^{-3}-10^{-2} \Omega \mathrm{cm}$ for bare AZO films. On the other hand, the resistivity of AZO films with a 30-nm-thick a-Si capping layer remained below $10^{-4} \Omega \mathrm{cm}$, even after TPJ annealing at a $T_{\max }$ of $825{ }^{\circ} \mathrm{C}$. The film crystallization of both AZO and a-Si layers was promoted without the formation of an intermixing layer. Additionally, the crystallization of phosphorous- and boron-doped a-Si layers at the sample surface was promoted, compared to that of intrinsic a-Si under the identical plasma annealing conditions. The TPJ annealing of $\mathrm{n}^{+}$-a-Si/textured AZO was applied for single junction $\mathrm{n}$-i-p microcrystalline Si thin-film solar cells.
\end{abstract}

\section{Introduction}

Silicon thin-film solar cells are a promising candidate for future photovoltaic power generation. The most advanced approach employs hydrogenated amorphous and microcrystalline silicon (a-Si:H, $\mu \mathrm{c}-\mathrm{Si}: \mathrm{H}$ ) as active layers in single and multi-junction cells, which are fabricated using a very-high-frequency (VHF) plasma-enhanced chemical vapor deposition method (PE-CVD) from a mixture of $\mathrm{SiH}_{4}$ and $\mathrm{H}_{2}$ [1,2]. Silicon thin-film solar cells in a $\mathrm{p}-\mathrm{i}-\mathrm{n}$ (superstrate) configuration require a transparent conductive oxide (TCO) films as a front contact. Such contacts must have a low series resistance and a high transparency in the visible and near-infrared regions. Furthermore, a surface topography is required to ensure lightscattering and subsequent light trapping inside the silicon solar cell structure [3,4]. Among various TCOs, impuritydoped zinc oxide, $\mathrm{ZnO}$, films such as $\mathrm{ZnO}: \mathrm{Al}$ (AZO) and $\mathrm{ZnO}: \mathrm{Ga}(\mathrm{GZO})$ are attractive because of their low material cost, non-toxicity, relatively low resistivity, and high visible transmission. In addition, AZO can be easily textured by wet chemical etching with diluted hydrochloric acid $(0.5 \% \mathrm{HCl})$. Recently, there has been particular interest in improving of the properties of impurity-doped $\mathrm{ZnO}$, i.e., the suppression of the free-carriers in multijunction Si thin-film solar cells [5]. Deposition of AZO and GZO films as a TCO have been extensively studied using several fabrication techniques, i.e., metal-organic chemical

\footnotetext{
a e-mail: shirai@fms.saitama-u.ac.jp
}

vapor deposition (CVD), magnetron sputtering, and solgel methods [6-10], followed by subsequent thermal annealing in vacuum to improve their optical and electrical properties. Among them, the thermal annealing of AZO with $\mathrm{n}^{+}$-a-Si capping layer on top of AZO is one of interests for further improvement of the performance of TCO films $[11,12]$. In addition, for further high efficiencies of single- and multi-junction solar cells, a new Si thin-film technology is needed, i.e., polycrystalline Si thin film and its alloys $[13,14]$.

In this study, we demonstrate the rapid thermal annealing for AZO film with and without an a-Si capping layer using an inductively-coupled radio-frequency (rf) argon thermal plasma jet (TPJ) at atmospheric pressure and applied for the n-i-p microcrystalline $\mathrm{Si}(\mu \mathrm{c}-\mathrm{Si})$ thin-film solar cells.

\section{Experimental details}

The 800-nm-thick AZO films used in this study were fabricated on corning 1737 glass $\left(25 \times 15 \mathrm{~mm}^{2}\right)$ using a rf magnetron sputtering technique in argon and a $99.99 \%$ AZO ceramic targets with 2 -wt $\%-\mathrm{Al}_{2} \mathrm{O}_{3}$ at a substrate temperature $T_{s}$ of $300{ }^{\circ} \mathrm{C}$ and a working pressure of $0.9 \mathrm{~Pa}$. The AZO was textured by wet chemical etching with diluted hydrochloric acid $\left(0.5 \% \mathrm{HCl}_{\mathrm{aq}}\right)$ [15]. The resistivity of the as-deposited AZO films was approximately $3-6 \times 10^{-4} \Omega \mathrm{cm}$. 30-nm-thick $\mathrm{n}^{+}-$and $\mathrm{p}^{+}$-a-Si:H layers were fabricated on flat and textured AZO-coated glass using a capacitively-coupled rf PE-CVD of a dichlorosilane 


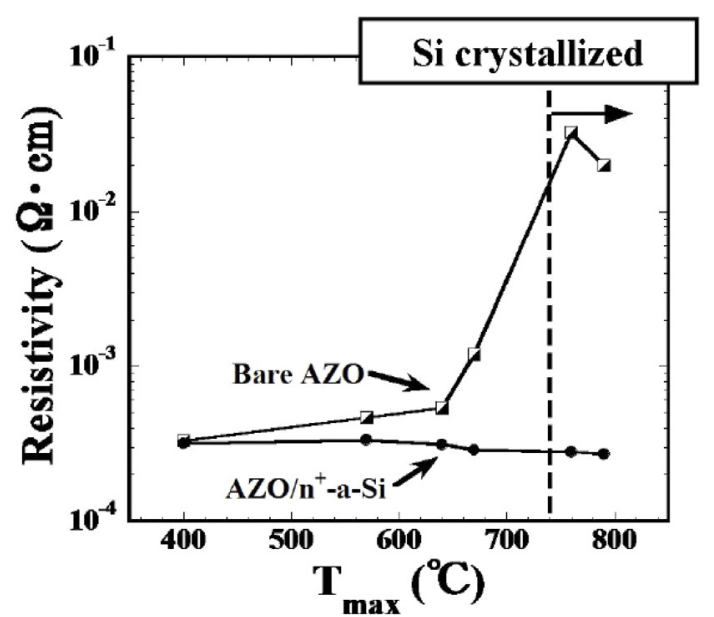

Fig. 1. Resistivity vs. maximum surface temperature $T_{\max }$ of AZO films with and without a $30-n m-$ thick $\mathrm{n}^{+}$-a-Si capping layer after TPJ annealing.

$\left(\mathrm{SiH}_{2} \mathrm{Cl}_{2}\right)$ and $\mathrm{H}_{2}$ mixture with and without an additional $1-\%-\mathrm{PH}_{3}\left(\mathrm{~B}_{2} \mathrm{H}_{6}\right)$, respectively, at a $T_{s}$ of $250{ }^{\circ} \mathrm{C}$. In the subsequent solar cell processing steps, much higher temperatures would be reached during thermal plasma exposure. Therefore, the a-Si:H films were pre-heated to $400{ }^{\circ} \mathrm{C}$ for $90 \mathrm{~min}$ prior to the thermal plasma annealing to remove the residual hydrogen from the films. The TPJ-annealing of $\mathrm{ZnO}$ and AZO films with and without an a-Si:H capping layer was performed with a variable substrate stage velocity $v_{s u b}$ and a $2 \mathrm{KW}$ inductively-coupled rf plasma source in a tri-axial quartz tube having an inner diameter of $10 \mathrm{~mm}$. The maximum surface temperature $T_{\max }$ was controlled by adjusting $v_{s u b}$. The quartz tube-substrate to substrate spacing was $15 \mathrm{~mm}$. The surface temperature profiles during TPJ annealing was monitored using a non-contact thermometry [16].

TPJ-annealed AZO and crystallized Si films were characterized by grazing incidence X-ray diffraction (GIXRD), X-ray photoelectron spectroscopy (XPS), photoluminescence (PL), and spectroscopic ellipsometry (SE). The Hall mobility $\mu$ and carrier density $N_{e}$ of the TPJannealed $\mathrm{ZnO}$ and $\mathrm{AZO}$ films were determined by a standard Van der Pauw method. The optical characterization of the textured AZO before and after TPJ annealing was performed using a double-beam UV-visible spectrometer equipped with an integrating sphere (Perkin Elmer, Lamda 35) at wavelengths ranging from 250 to $1800 \mathrm{~nm}$. The Si thin-film solar cells were fabricated with a singlejunction n-i-p $\mu \mathrm{c}-\mathrm{Si}$ solar cell structure. The $2-\mu \mathrm{m}$-thick $\mu \mathrm{c}$-Si layer was fabricated from a $\mathrm{SiH}_{2} \mathrm{Cl}_{2}$ and $\mathrm{H}_{2}$ mixture at $500{ }^{\circ} \mathrm{C}$

\section{Results}

\subsection{TPJ annealing of $\mathrm{ZnO}$ and $\mathrm{AZO}$ films with and without an a-Si capping layer}

Figure 1 shows the resistivity of AZO films with and without capping $30-n m$-thick $\mathrm{n}^{+}$-a-Si layer upon the TPJ

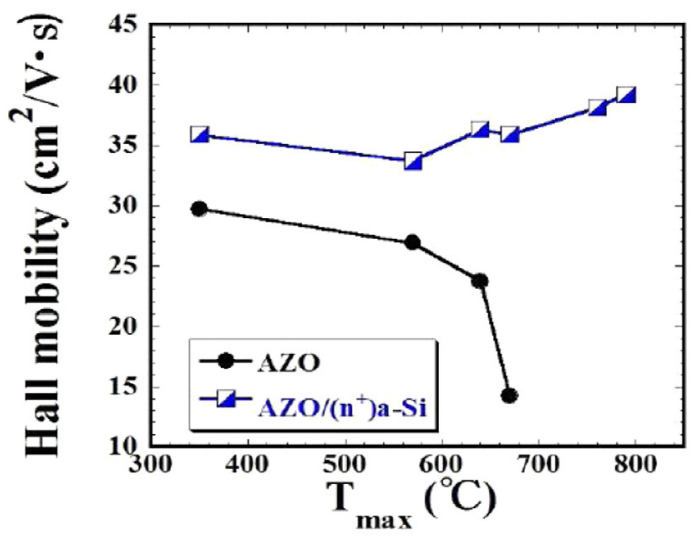

(a)

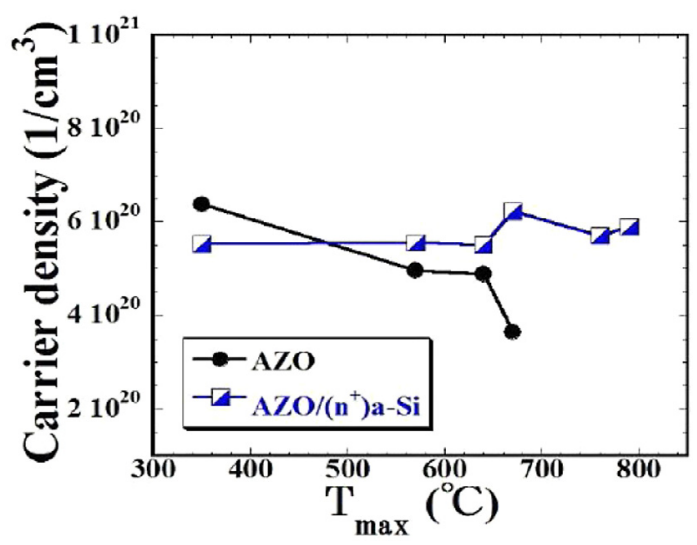

(b)

Fig. 2. (a) Hall mobility $\mu$ and (b) carrier density $N_{e}$ of TPJannealed AZO films at different $T_{\max }$. The $\mathrm{n}^{+}$-Si layer on top of AZO was etched out using reactive ion etching after TPJ annealing. The TPJ annealing was performed by changing $v_{\text {sub }}$ from 55 to $22 \mathrm{~mm} / \mathrm{s}$.

annealing plotted against $T_{\max }$. Here, the TPJ annealing was performed on the identical region by repeating the plasma exposure at $v_{s u b} \mathrm{~s}$ from 55 down to $10 \mathrm{~mm} / \mathrm{s}$ to minimize the thermal damage of previous annealing history. The resistivity increased markedly from $10^{-4}$ to $10^{-2} \Omega \mathrm{cm}$ at $T_{\max } \mathrm{s}$ above $650{ }^{\circ} \mathrm{C}$ for bare AZO films on glass. On the other hand, it increased slightly and/or was almost independent of $v_{\text {sub }}$ of an order of $10^{-4} \Omega \mathrm{cm}$ up to a $T_{\max }$ of $825{ }^{\circ} \mathrm{C}\left(v_{\text {sub }}: 25 \mathrm{~mm} / \mathrm{s}\right)$ for AZO films with a 30 -nm-thick $\mathrm{n}^{+}$-a-Si capping layer. The film crystallization of both a$\mathrm{Si}$ and AZO layers was observed at $T_{\max }$ above $740{ }^{\circ} \mathrm{C}$. These results agreed qualitatively with those of conventional solid-phase-crystallization (SPC) of $n^{+}$-a-Si coated AZO films at $600{ }^{\circ} \mathrm{C}$ for $22 \mathrm{~h}[11,12]$. Similar result was also obtained in the AZO films capping $\mathrm{p}^{+}$-a-Si layer. Similar results were also observed in the boron-doped and intrinsic a-Si layers.

In Figure 2, the $\mu$ and $N_{e}$ of TPJ-annealed $\mathrm{ZnO}$ and AZO layers with and without a-Si capping layers are summarized as a function of $T_{\max } \mathrm{s}$. The Hall measurement was performed for TPJ-annealed AZO films on flat glass after etching out top $\mathrm{n}^{+}-\mu \mathrm{c}-\mathrm{Si}$ layer. The $\mu$ and $N_{e}$ in bare 

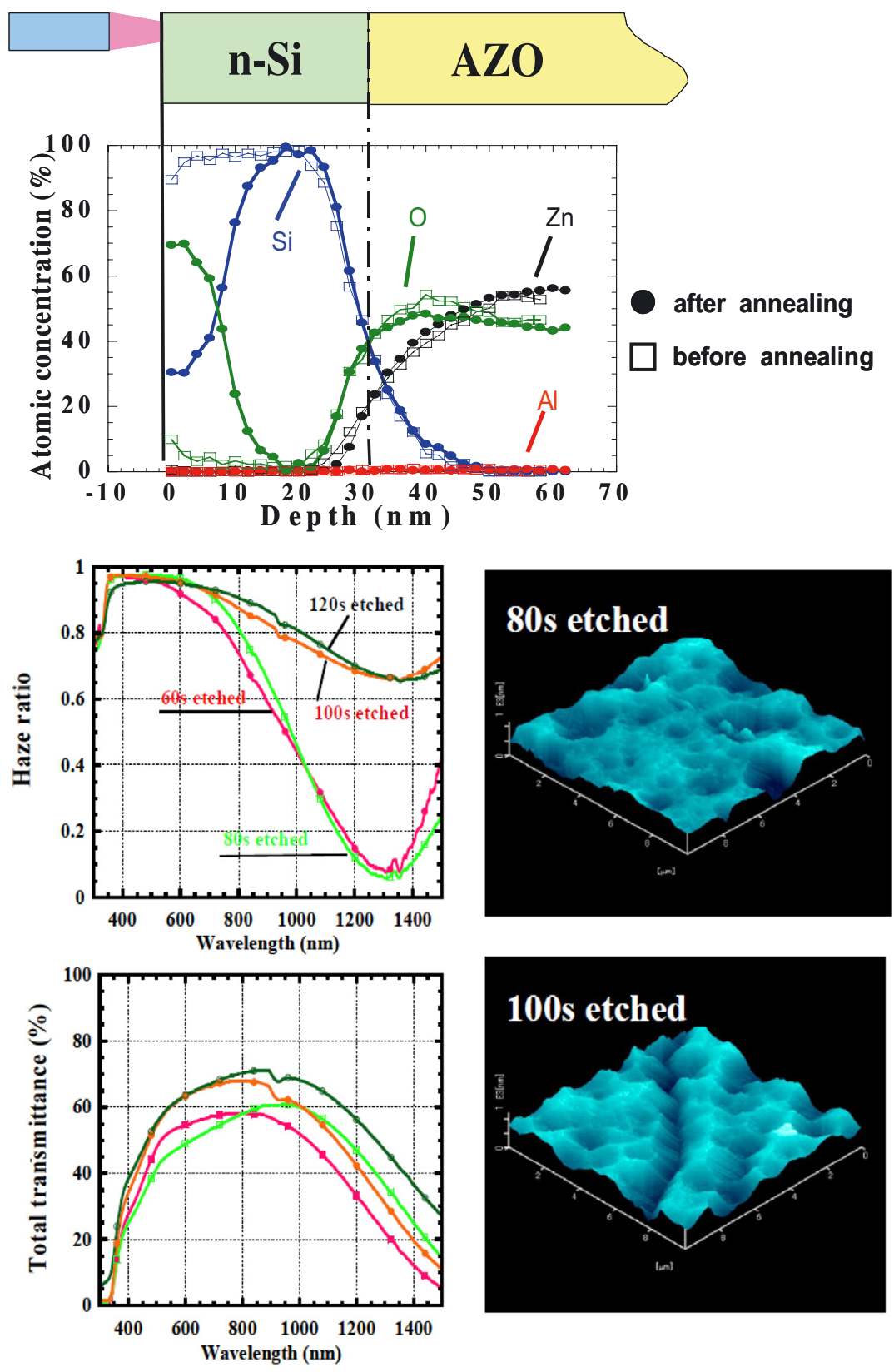

Fig. 3. Depth profiles of atomic concentrations, $\mathrm{Si}, \mathrm{Zn}, \mathrm{Al}$, and $\mathrm{O}$ for $\mathrm{n}^{+}$-a-Si/AZO heterostructures before and after TPJ annealing monitored by XPS. The measurement was performed each after 5-nm-thick etching by Ar plasma.
Fig. 4. Total transmittance $T_{\text {total }}$ and haze spectra of TPJ-annealed AZO films with different surface morphology. The wet chemical etching was conducted after TPJ annealing by a $0.5 \% \mathrm{HCl}$ at different dipping times. The TPJ annealing was performed at a $v_{\text {sub }}$ of $25 \mathrm{~mm} / \mathrm{s}$ and a $T_{\max }$ of $650{ }^{\circ} \mathrm{C}$. The inset shows the AFM images of the 80 and 100 s chemically etched AZO film.
ZnO films decreased to $13-18 \mathrm{~cm}^{2} / \mathrm{V}$ s and $3 \times 10^{20} \mathrm{~cm}^{-3}$, respectively, with increasing $T_{\max }$. On the other hand, the $\mu$ increased from 30 to $39 \mathrm{~cm}^{2} / \mathrm{V}$ s for $\mathrm{AZO}$ with $\mathrm{n}^{+}$a-Si capping layer. While, the $N_{e}$ was almost independent of $v_{\text {sub }}$ and remained on the order of $10^{20} \mathrm{~cm}^{-3}$ even after TPJ annealing at a $T_{\max }$ of $825^{\circ} \mathrm{C}$. These results suggest that the film crystallization of AZO layer promoted with any increase in the $\mathrm{O}$ and $\mathrm{Zn}$ related defects. The PL characterization also revealed that the generation of $\mathrm{O}$ and $\mathrm{Zn}$ related defects was suppressed by the a-Si capping layer.

Depth profiles of the atomic concentrations of $\mathrm{Si}, \mathrm{Zn}$, $\mathrm{Al}$, and $\mathrm{O}$ of the $\mathrm{AZO}$ a $30-\mathrm{nm}$-thick $\mathrm{n}^{+}$-a-Si capping layer are shown in Figure 3, as measured by XPS before and after TPJ annealing. No significant changes in the depth profiles of $\mathrm{Al}, \mathrm{Zn}$, or $\mathrm{Si}$ and thicknesses were observed in the $\mathrm{Si} / \mathrm{AZO}$ heterostructure except for the formation of an oxidized Si layer at the top surface. In addition, the SE characterization also revealed that the film crystallization of a-Si ansd AZO layers was enhanced and no significant generation of intermixing layer were formed at a-Si and AZO interface. These findings imply that the film crystallization of both AZO and Si layers was enhanced without significant oxygen diffusion from underlying AZO to top a-Si layer.

\subsection{Texturing of $A Z O$ and its effect of the crystallization of a-Si capping layer}

Figure 4 shows the total transmittance $T_{\text {total }}$ and haze spectra of TPJ-annealed AZO films with different surface morphology. The TPJ annealing was conducted at a $T_{\max }$ 


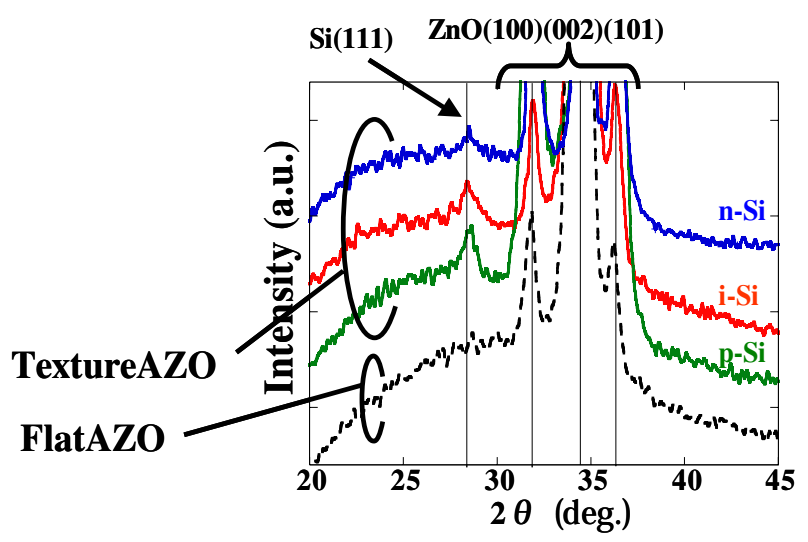

Fig. 5. GI-XRD patterns of TPJ-annealed 30 -nm-thick $\mathrm{n}^{+}-$, $\mathrm{p}^{+}-$, and intrinsic- crystallized Si films on textured AZO-coated glass substrates after TPJ annealing at a $T_{\max }$ of $825^{\circ} \mathrm{C}$. The result of intrinsic- crystallized $\mathrm{Si}$ on flat $\mathrm{AZO}$ is also shown as a reference.

of $650{ }^{\circ} \mathrm{C}$ and subsequently, the wet chemical etching using a $0.5 \% \mathrm{HCl}$ was carried out at different dipping times for $2-\mu \mathrm{m}$-thick AZO films. The AFM image of corresponding textured AZO is also shown on the top. The uniform crater structures were formed by adjusting the $\mathrm{HCl}$ rinse time. High haze values were obtained of above $70 \%$ in entire spectra range for $\sim 100 \mathrm{~s}$ (800 nm thickness) etched AZO films. The $T_{\text {total }}$ in the $1000-1200 \mathrm{~nm}$ regions corresponding to the free carrier absorption was also suppressed with increasing the $\mathrm{HCl}$ etching time. These results originate from less free carrier density. The Hall measurement revealed that the $\mu$ and $N_{e}$ were $45 \mathrm{~cm}^{2} / \mathrm{V} \mathrm{s}$ and $10^{20} \mathrm{~cm}^{-3}$ in the $100 \mathrm{~s}$ etched AZO films. On the other hand, the TPJ annealing of $\mathrm{HCl}$-etched AZO films showed relatively high resistivity because the etching speed was higher. Thus, the texturing of AZO was conducted after TPJ annealing to design the optical management without deteriorating electrical properties.

In Figure 5, the GI-XRD patterns are shown for the 30nm-thick $\mathrm{n}^{+}{ }_{-}, \mathrm{p}^{+}{ }_{-}$, and intrinsic-crystallized Si films fabricated on textured AZO-coated glass substrates after TPJ annealing. The result of intrinsic-crystallized Si film on flat AZO is also shown as a reference. Apparently, both Si and AZO layers were crystallized by the TPJ annealing for all samples, although the degree of the film crystallization depended on the impurity concentration and film thickness. In addition, the Si (111) diffraction peak intensities in intrinsic-, $\mathrm{n}^{+}$-, and $\mathrm{p}^{+}$-a-Si films were enhanced on textured AZO rather than the flat. Similar results were also reported elsewhere for $\mathrm{p}-\mathrm{i}-\mathrm{n} \mu \mathrm{c}-\mathrm{Si}$ thin-film solar cells [17]. These results originate from that SPC of a-Si by TPJ annealing is promoted not from the top surface but the bottom. These results suggest that the texturing AZO surface promotes the inhomogeneous temperature profile toward the film depth, which is a possible origin to enhance the nucleation and grain growth rather than the flat. Therefore, the use of texturing AZO is effective to promote the film crystallization of top a-Si layer, although its degree depends on impurity type, $\mathrm{P}$ and $\mathrm{B}$, and their concentrations in a-Si precursors. These findings imply that the
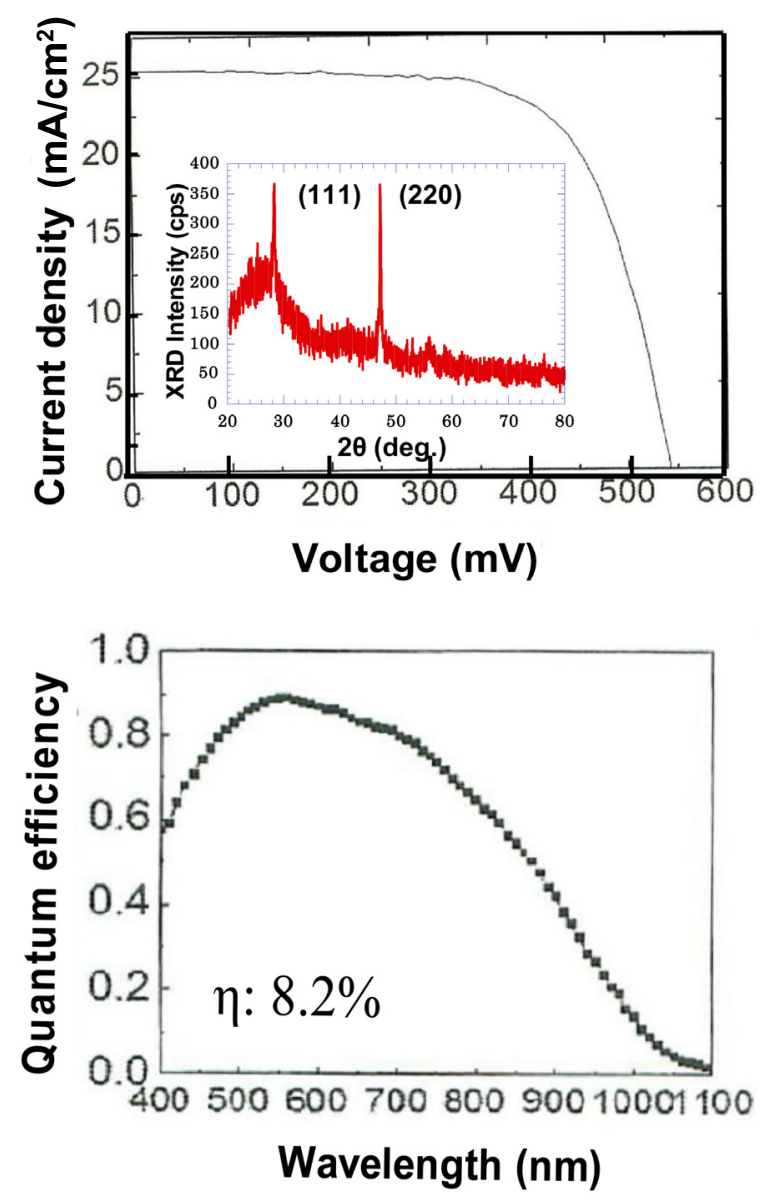

Fig. 6. $I-V$ characteristics and QE spectra of n-i-p $\mu \mathrm{c}-\mathrm{Si}$ thinfilm solar cells with textured AZO. The intrinsic $\mu \mathrm{c}-\mathrm{Si}: \mathrm{H}: \mathrm{Cl}$ layer used was $2 \mu \mathrm{m}$ thickness and fabricated from a $\mathrm{SiH}_{2} \mathrm{Cl}_{2}$ and $\mathrm{H}_{2}$ mixture by rf PE-CVD. Inset shows the XRD pattern of corresponding $\mu \mathrm{c}-\mathrm{Si}$ films.

TPJ annealing of $\mathrm{n}^{+}$-a-Si/textured AZO heterostructure is a possible technique for the optical management for $\mathrm{Si}$ thin-film solar cells.

Figure 6 shows the current-voltage, $I-V$ curve and quantum efficiency $(\mathrm{QE})$ spectra of $\mu \mathrm{c}-\mathrm{Si}$ single-junction solar cells using textured AZO. Inset shows the corresponding $\mu \mathrm{c}-\mathrm{Si}$ film. The current density $J_{s c}$ improved markedly with no decrease in open circuit voltage $V_{o c}$ by introducing the textured AZO because of better light scattering. The efficiency of $8.2 \% \quad\left(V_{o c}: 542 \mathrm{mV}, J_{s c}\right.$ : $25.4 \mathrm{~mA} / \mathrm{cm}^{2}$, FF: $68 \%$ ) has been obtained for $\mu \mathrm{c}-\mathrm{Si}: \mathrm{H}$ n-i-p solar cell with $2 \mu \mathrm{m}$ i-layer and $0.253 \mathrm{~cm}^{2}$ area at a deposition rate of $5 \AA / \mathrm{s}$. These findings suggest that the TPJ annealing of AZO with $\mathrm{n}^{+}$-a-Si capping layer is a possible method for further high performance of $\mu \mathrm{c}-\mathrm{Si}$ thin-film solar cells at high temperature regime.

\section{Conclusions}

We demonstrated the effects of a-Si capping layers on $\mathrm{ZnO}: \mathrm{Al}$ (AZO) during rf thermal plasma jet annealing. Both AZO and a-Si layers were crystallized by the TPJ 
annealing at a maximum surface temperature $T_{\max }$ above $825{ }^{\circ} \mathrm{C}$. In addition, the film crystallization of a-Si layer was promoted efficiently on textured AZO by TPJ annealing with no significant diffusion of oxygen at the interface. The role of a-Si capping layer on AZO during TPJ annealing is the suppression of the fluctuation of the band potential due to the segregation of $\mathrm{Al}_{2} \mathrm{O}_{3}$ phase in $\mathrm{ZnO}$. Higher haze values above $70 \%$ were obtained in the entire spectra range from 400 to $1500 \mathrm{~nm}$ maintaining.

This work was supported partially by a Grant-in-Aid for Scientific Research from the Ministry of Education, Culture, Sports, Science and Technology of Japan.

\section{References}

1. B. Rech, T. Repmann, S. Wieder, M. Rusuke, U. Stephan, Thin Solid Films 502, 300 (2006)

2. K. Yamamoto, M. Yoshimi, Y. Tawada, S. Fukuda, S. Sawada, T. Meguro, H. Takata, T. Suezaki, Y. Koi, K. Hayashi, T. Suzuki, M. Ichikawa, A. Nakajima, Sol. Enery Mater. Sol. Cells 74, 449 (2002)

3. B. Rech, H. Wagner, Appl. Phys. A 69, 155 (1999)

4. S.J. Tark, M.G. Kang, S. Park, J.H. Jang, J.C. Lee, W.M. Kim, J.S. Lee, D. Kim, Thin Solid Films 9, 1318 (2009)

5. O. Kluth, B. Rech, L. Houben, S. Wieder, G. Schope, C. Beneking, H. Wagner, A. Loffl, H.W. Schock, Thin Solid Films 351, 247 (1999)
6. S. Mridha, D. Bask, J. Phys. D 40, 6902 (2007)

7. M. Suchea, S. Christoulakis, N. Katsarakis, T. Kisopoulos, G. Kiriakidis, Thin Solid Films 51, 6562 (2007)

8. B.-Z. Dong, H. Hu, G.J. Fang, X.Z. Zhao, D.Y. Zheng, Y.P. Sun, J. Appl. Phys. 103, 073711 (2007)

9. R. Romero, D. Leinen, E.A. Dalchiele, J.R. RamosBurrado, F. Martin, Thin Solid Films 515, 1942 (2006)

10. M. Volintiru, B. Creatore, J. Kniknie, C.I.M.A. Spee, M.C. Van de Sanden, J. Appl. Phys. 102, 043709 (2007)

11. C. Becker, E. Conrad, P. Dogan, F. Fenske, B. Gorka, T. Hanel, K.Y. Lee, B. Rau, F. Ruske, T. Weber, M. Berginski, J. Hupkes, S. Gall, B. Rech, Sol. Energy Mater. Sol. Cells 93, 825(2009)

12. S. Gall, C. Becker, E. Conrad, P. Dogan, F. Fenske, B. Gorka, K.Y. Lee, F. Ruske, B. Rech, Sol. Energy Mater. Sol. Cells 93, 1004 (2009)

13. B. Rech, T. Repmann, M.N. Van den Donker, M. Berginski, T. Kilper, J. Hupkes, S. Calnan, H. Stiebig, S. Wieder, Thin Solid Films 511-522, 548 (2006)

14. K.Y. Lee, C. Becker, M. Muske, Appl. Phys. Lett. 91, 241911 (2007)

15. O. Kluth, B. Rech, L. Houben, S. Wieder, G. Schope, C. Beneking, H. Wagner, A. Loffl, H.W. Schock, Thin Solid Films 251, 247 (1999)

16. N. Ohta, T. Imamura, H. Shimizu, T. Kobayashi, H. Shirai, Phys. Stat. Sol. A 207, 574 (2010)

17. H. Shirai, Y. Sakurai, M. Ye, K. Haruta, T. Kobayashi, Proc. Matter. Res. Soc. Symp. Proc. 989, 0989-A13-04 (2007) 